\title{
Ribbon Çatısına göre Roller Coaster Yüzeyinin Karakterizasyonları
}

\author{
Selçuk BAŞ* \\ Muş Alparslan Üniversitesi, Malazgirt Meslek Yüksekokulu, Muş
}

\begin{abstract}
Öz
Diferansiyel geometride 3-boyutlu Öklid uzayında yüzeylerin önemli bir sınıfi olan ve 1-parametreli diferansiyellenebilir doğru aileleri ile elde edilen regle ve açılabilir yüzeyler bilgisayar destekli dizayn programlarında, inşaat mühendisliğinde, mimarlık alanlarında önemli bir yere sahiptir. Ayrıca, robotik ve mekaniksel bazı işleyişlerin çalışma yolu ve çalışma alanlarını üreten süreçler uzaysal eğri ve yüzeyler ile oluşturulur. Bu eğri ve yüzeyleri anlamak için diferansiyel geometriye başvurulması ise gayet doğal bir yaklaşım olacaktır. Dairesel yüzeyler de tıpkı regle yüzeyler gibi birçok alanda kullanılan önemli bir konudur. Bir eğri yardımıyla elde edilen kanal ve tüp yüzeyler ise dairesel yüzeylere verilecek en önemli yüzey ailelerindendir. Roller coasterler trenin; virajların, halkaların, tepelerin ve vadilerin etrafinda hareket ederken kinetik ve potansiyel enerjinin etkileşimi ile klasik enerji dönüşümlerine örnektirler. Bir roller coaster pisti, uzayda hareket eden bir parçacığın uzayda verilen bir eğri üzerinde kalacaktır. Roller Coaster yüzeyi dairesel yüzeylerin özel bir tipidir. Bu çalışmada, 3-boyutlu Öklid uzayında Ribbon çatısıyla $\mathfrak{R}$-Roller Coaster yüzeyi araştırıldı. Dahası, $\mathfrak{R}$-Roller Coaster yüzeyinin 1. ve 2. Temel formun katsayısı, ortalama eğriliği, Gauss eğrilikleri incelemiştir. Ayrıca, $\mathfrak{R}$ Roller Coaster yüzeylerinin paralel yüzeyleri elde edildi. Son olarak, bir $\mathfrak{R}$-Roller Coaster yüzeyinin elastik olmayan akışına karşıllık gelen denklemler bulundu.
\end{abstract}

Anahtar kelimeler: Roller Coaster yüzeyi, Ribbon çatı, Dairesel yüzey, Paralel yüzey.

\section{Characterizations of Roller Coaster Surface According to Ribbon Frame}

\begin{abstract}
In differential geometry, the research of certain classes of surfaces with particular features in 3-dimensional Euclidean space such as ruled and developable surfaces, which are 1-parameter smooth families of straight lines, has a significant role in the field of CAD, civil engineering, and architecture. Moreover, the work path and workspace of robotic or mechanic operations are formed by these spatial curves and surfaces respectively during the generation process. Thus, it is reasonable to make use of differential geometry in order to understand these surfaces and spatial curves. Circular surfaces are also regarded as a highly essential topic in a different area like as ruled surfaces. A canal surface and tube surface of a space curve can be given as one of the important class of examples of circular surface. Roller coasters are usual examples of energy transformation, with an interaction of kinetic and potential energy as the train moves surrounding the curves, loops, hills and valleys of the path. A roller coaster path so that a particle moving in space will stay on a given curve in space. The roller coaster surface is a special type of spherical surfaces. In this study, $\mathfrak{R}$-Roller Coaster surfaces with Ribbon frame is investigate in Euclidean 3-space. Moreover, the Gaussian curvature, mean curvature, first and second fundamental form of coefficients of Roller Coaster surfaces of are examined. Then, the parallel surfaces of $\mathfrak{R}$-Roller Coaster surfaces of are obtained. Finally, we derive the related equations for the inextensible flow of a $\mathfrak{R}$-Roller Coaster surface.
\end{abstract}

Keywords: Roller Coaster surfaces, Ribbon frame, Circular surface, Parallel surfaces.

*Sorumlu yazar: slckbs@hotmail.com

Geliş Tarihi: 08.06.2018, Kabul Tarihi: 23.11.2018 


\section{Introduction}

Roller coasters provide many excellent examples to use when teaching about statics, kinematics, forces, vectors, dynamics and energy conservation. A roller coaster path so that a particle moving in space will stay on a given curve in space. The geometric description of the curve for a roller coaster track starts with the definition of a moving referential, in which the tangent, normal and binormal vectors define an orthogonal frame. Hollis [1] considered how to create monorail roller coaster animations (figure 1) in which the track is a surface in $E^{3}$ in the form of a narrow strip.

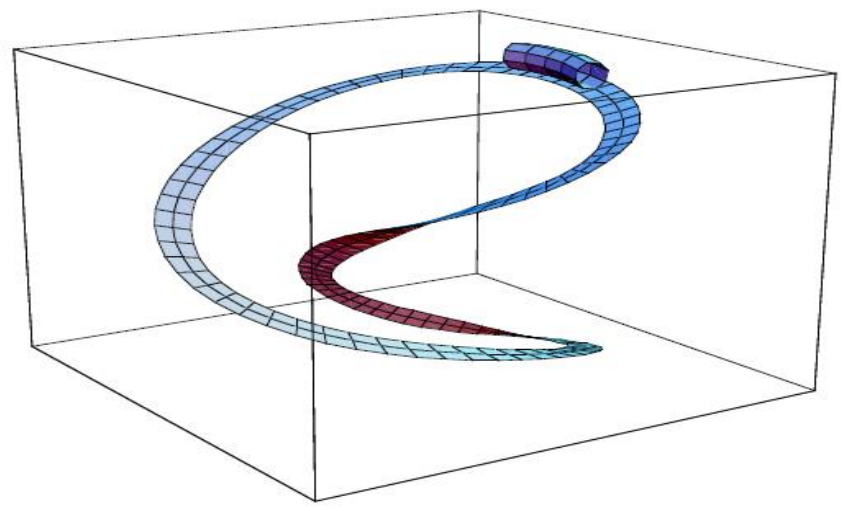

Figure 1. Roller Coaster Animations [1].

A standart circular surface provides the characteristic the fact that the mix part is definitely a ring and so the unit normal in the circle plane can be totally parallel to the mix component. Presently there are a large number of different titles intended for one of the standart circular surface in earlier materials, that is , tubular surface [2,3,4], pipe surface [5] and canal surface [6,7,8]. A canal surface as well express the envelope of a family of circles by way of variable radius. Carmo [9] investigated a few geometric features of standart circular surfaces and demonstrated two significant theorems in applied geometry regarding the total curvature of space curves, specifically, Fenchel's theorem and the FaryMilnor theorem. The roller coaster surface is a special type of circular surfaces. Roller coaster surface which is similar to the tangent developable of a space curve. Abdel-Baky etc. [10] considered spacelike roller coaster surfaces which are defined as spacelike circular surfaces whose generating circles are lines of curvature. Finally, the authors investigated geometric properties of them. A nonstandart circular surface has the characteristic that the cross section is not a circle and the normal of the circle plane is generally not parallel to that of the cross component. Izumiya etc. [11] researched the singularities of circular surfaces. Cui etc. [12] studied applied geometry of nonstandart circular surfaces by way of a fixed radius.

Bohr [13] researched a basic explanation of developable ribbons applying a ruled process where ribbons are unmatched defined by two producing functions. Baş etc. [14] researched inextensible flow of curves with Ribbon frame in the Euclidean 3-space $\mathrm{E}^{3}$.

In this study, Roller Coaster surfaces with Ribbon frame is introduced in Euclidean space 3space. The Gaussian curvature, mean curvature, first and second fundamental form of coefficients of Roller Coaster surfaces of are examined. We characterize Roller Coaster surfaces in the Euclidean space 3-space.

\section{Preliminaries}

For the construction of ribbon and the center curve of the ribbon we need two smooth functions, $p(s)$ and $\theta(s)$. We also assume that they are described in the interval $s \in[0, Z]$, where $Z$ is the essential length of the ribbon beneath building. We also suppose that $\theta(s) \in[0, \pi] \forall s$ and $\sin (\theta(s))>0 \forall s$, througout the paper. In this construction unit vector field $A(s)$ is significant since it is defined by having 
the angle $\theta(s)$ to the center curve of the ribbon and it is also a field tangent to the ribbon. Actually, $A(s)$ will generate the Darboux vector $D(s)$ since it is a direction field together with the generating function $p(s)$ as a product factor, i.e. $D(s)=p(s) J(s)$.

We assume that $\{\mathbf{c}(s), \mathbf{v}(s), \mathbf{h}(s)\}$ are unique orthonormal vectors such that they are solutions to the below system:

$\mathbf{c}^{\prime}(s)=p(s) J(s) \times \mathbf{c}(s)$,

$\mathbf{v}^{\prime}(s)=p(s) J(s) \times \mathbf{v}(s)$,

$\mathbf{h}^{\prime}(s)=p(s) J(s) \times \mathbf{h}(s)$,

where $J(s)$ is defined in terms of $\mathbf{h}(s)$ and $\mathbf{c}(s)$ as the following:

$$
J(s)=\sin (\theta(s)) \mathbf{h}(s)+\cos (\theta(s)) \mathbf{c}(s) .
$$

For the purpose of uniqueness we also implement arbitrary initial conditions referring to a basis in $\mathrm{R}^{3}$ for given fixed coordinate system

$$
\{\mathbf{c}(0), \mathbf{v}(0), \mathbf{h}(0)\}=\{(1,0,0),(0,1,0),(0,0,1)\} .
$$

The above system is stated as follows explicitly:

$$
\begin{aligned}
\mathbf{c}^{\prime}(s) & =p(s) \sin (\theta(s)) \mathbf{v}(s) \\
\mathbf{v}^{\prime}(s) & =-p(s) \sin (\theta(s)) \mathbf{c}(s)+p(s) \cos (\theta(s)) \mathbf{h}(s), \\
\mathbf{h}^{\prime}(s) & =-p(s) \cos (\theta(s)) \mathbf{v}(s),
\end{aligned}
$$

where the dot notation denotes differentiation according to $\mathrm{s}$ If we consider notation of compact matrix, then we have

$$
\mathbf{R}^{\prime}(s)=\mathbf{R}(s) \boldsymbol{\Xi}(s),
$$

where $\mathbf{R}(s)$ is the orthogonal matrix so that it satisfies $2 \operatorname{det}(\mathbf{R}(s))=1$. Further, columns of the $\mathbf{R}(s)$ are the coordinate functions of $\{\mathbf{c}(s), \mathbf{v}(s), \mathbf{h}(s)\}$ respectively [13], where

$$
\boldsymbol{\Xi}(s)=\left[\begin{array}{ccc}
0 & -p(s) \sin (\theta(s)) & 0 \\
p(s) \sin (\theta(s)) & 0 & -p(s) \cos (\theta(s)) \\
0 & p(s) \cos (\theta(s)) & 0
\end{array}\right] .
$$

Let $\mathrm{N}$ be the standard unit normal vector field on a surface $\Psi$ described by

$$
\mathrm{N}=\frac{\Psi_{s} \wedge \Psi_{u}}{\left\|\Psi_{s} \wedge \Psi_{u}\right\|}
$$

where $\Psi_{s}=\frac{\partial \Psi(s, u)}{\partial s}$. Then, the functions

$$
\mathrm{E}=\left\langle\Psi_{s}, \Psi_{s}\right\rangle, \mathrm{F}=\left\langle\Psi_{s}, \Psi_{u}\right\rangle, \mathrm{G}=\left\langle\Psi_{u}, \Psi_{u}\right\rangle,
$$


are denoted to be the coeccients of the first fundamental form and the functions

$$
l=\left\langle\Psi_{s s}, \mathrm{~N}\right\rangle, m=\left\langle\Psi_{s u}, \mathrm{~N}\right\rangle, n=\left\langle\Psi_{u u}, \mathrm{~N}\right\rangle,
$$

are defined to form the second fundamental form of $\Psi$.

Additionally, the invariant functions of the Gaussian curvature $\mathrm{K}$ and the mean curvature $\mathrm{H}$ of the surface are defined as follows:

$$
\begin{gathered}
\mathrm{K}=\frac{e g-f^{2}}{\mathrm{EG}-\mathrm{F}^{2}}, \\
\mathrm{H}=\frac{\mathrm{E} g-2 \mathrm{~F} f+\mathrm{G} e}{2\left(\mathrm{EG}-\mathrm{F}^{2}\right)},
\end{gathered}
$$

respectively, [9].

Definition 2.1. [15], A surface evolution $\Psi(s, v, t)$ is its flow $\frac{\partial \Psi}{\partial t}$ are said to be inextensible if its first fundamental form $\{E, F, G\}$ satisfies

$$
\frac{\partial \mathrm{E}}{\partial t}=\frac{\partial \mathrm{F}}{\partial t}=\frac{\partial \mathrm{G}}{\partial t}=0
$$

Definition 2.2. A circular surface is a map

$$
\mathrm{L}: I \times \mathrm{R} / 2 \pi \mathrm{Z} \rightarrow \mathrm{E}^{3}
$$

defined by

$$
\mathrm{L}(t, v)=\gamma(t)+r(t)\left(c_{1}(t) \cos v+c_{2}(t) \sin v\right),
$$

where $\gamma, c_{1}, c_{2}: I \rightarrow \mathrm{E}^{3}$ and $r: I \rightarrow \mathrm{R}_{>0}$. We call $\gamma a$ base curve and a pair of two curves $c_{1}, c_{2} a$ director frame. The standard circles

$v \mapsto \gamma(t)+r\left(c_{1}(t) \cos v+c_{2}(t) \sin v\right)$

are called generating circles, [11].

\section{Roller Coaster Surface According to Ribbon Frame in $E^{3}$}

In respect to the Ribbon frame $(\mathbf{c}(s), \mathbf{v}(s), \mathbf{h}(s))$ the parametric expression of the $\mathfrak{R}$-roller coaster surfaces is given by:

$\Psi^{\mathrm{R}}(s, u)=\gamma(s)+r \cos u \mathbf{c}(s)+r \sin u(\cos \varphi(s) \mathbf{v}(s)+\sin \varphi(s) \mathbf{h}(s))$.

Proposition 3.1. Assume the spin curve of a $\Re$-roller coaster surface is a unit speed curve $\beta: I \rightarrow \mathrm{E}^{3}$ with nonzero curvature. So, Gaussian curvature of $\Re$-roller coaster surface $\Psi^{\mathrm{R}}(s, u)$ is given by

$$
\begin{aligned}
& \mathrm{K}=\frac{1}{\Gamma \Lambda^{2}}\left[\left(\lambda_{2} \mu_{3}\right)\left(\left(\lambda_{1}\right)_{s}-p \lambda_{2} \sin \theta\right)-\left(\left(\lambda_{2}\right)_{s}+p \lambda_{1} \sin \theta\right)\left(\lambda_{1} \mu_{3}\right)\right. \\
& \left.+\left(p \lambda_{2} \cos \theta\right)\left(\lambda_{1} \mu_{2}+\lambda_{2} \mu_{1}\right)\right]\left[\left(\lambda_{2} \mu_{3}\right)\left(\mu_{1}\right)_{u}-\left(\lambda_{1} \mu_{3}\right)\left(\mu_{2}\right)_{u}\right. \\
& \left.\left.+\left(\lambda_{1} \mu_{2}+\lambda_{2} \mu_{1}\right)\left(\mu_{3}\right)_{u}\right]-\left[\left(\lambda_{2} \mu_{3}\right)\left(\lambda_{1}\right)_{u}-\left(\lambda_{1} \mu_{3}\right)\left(\lambda_{2}\right)_{u}+\left(\lambda_{1} \mu_{2}+\lambda_{2} \mu_{1}\right) \lambda_{3}\right)_{u}\right]^{2}
\end{aligned}
$$


where

$\lambda_{1}=(1-r p \sin u \cos \varphi \sin \theta)$,

$\lambda_{2}=(r p \cos u \sin \theta)$,

$\mu_{1}=-r \sin u$

$\mu_{2}=r \cos u \cos \varphi$

$\mu_{3}=r \cos u \sin \varphi$

$\Lambda=\sqrt{\left[\lambda_{2} \mu_{3}\right]^{2}+\left[\lambda_{1} \mu_{3}\right]^{2}+\left[\lambda_{1} \mu_{2}+\lambda_{2} \mu_{1}\right]^{2}}$,

and

$\Gamma=r^{2}\left[(1-r \sin u \cos \varphi w \sin \theta)^{2}+(r w \cos u \sin \theta)^{2}\right]-\left(r \sin \theta+r^{2} w \cos \varphi \sin \theta\right)^{2}$.

Proof. We have the natural frame $\Psi_{s}^{\mathrm{R}}, \Psi_{u}^{\mathrm{R}}$ of the surface $\Psi^{\mathrm{R}}(s, u)$ given by

$\Psi_{s}=(1-r p \sin u \cos \varphi \sin \theta) \mathbf{c}+(r p \cos u \sin \theta) \mathbf{v}$,

$\Psi_{u}=(-r \sin u) \mathbf{c}+(r \cos u \cos \varphi) \mathbf{v}+(r \cos u \sin \varphi) \mathbf{h}$.

The quantities E, F, G are calculated to be

$\mathrm{E}=(1-r p \sin u \cos \varphi \sin \theta)^{2}+(r p \cos u \sin \theta)^{2}$,

$\mathrm{F}=-r \sin u+r^{2} p \cos \varphi \sin \theta$,

$\mathrm{G}=r^{2}$.

Additionally, the unit normal vector field $\mathrm{N}$ at any point is

$$
\mathrm{N}=\frac{1}{\Lambda}\left[\left(\lambda_{2} \mu_{3}\right) \mathbf{c}-\left(\lambda_{1} \mu_{3}\right) \mathbf{v}+\left(\lambda_{1} \mu_{2}+\lambda_{2} \mu_{1}\right) \mathbf{h}\right],
$$

where

$\lambda_{1}=(1-r p \sin u \cos \varphi \sin \theta)$,

$\lambda_{2}=(r p \cos u \sin \theta)$,

$\mu_{1}=-r \sin u$,

$\mu_{2}=r \cos u \cos \varphi$,

$\mu_{3}=r \cos u \sin \varphi$,

$\Lambda=\sqrt{\left[\lambda_{2} \mu_{3}\right]^{2}+\left[\lambda_{1} \mu_{3}\right]^{2}+\left[\lambda_{1} \mu_{2}+\lambda_{2} \mu_{1}\right]^{2}}$.

Components of second fundamental form are

$l=\frac{1}{\Lambda}\left[\left(\lambda_{2} \mu_{3}\right)\left(\left(\lambda_{1}\right)_{s}-p \lambda_{2} \sin \theta\right)-\left(\left(\lambda_{2}\right)_{s}+p \lambda_{1} \sin \theta\right)\left(\lambda_{1} \mu_{3}\right)\right.$

$\left.+\left(p \lambda_{2} \cos \theta\right)\left(\lambda_{1} \mu_{2}+\lambda_{2} \mu_{1}\right)\right]$, 


$$
\begin{aligned}
& m=\frac{1}{\Lambda}\left[\left(\lambda_{2} \mu_{3}\right)\left(\lambda_{1}\right)_{u}-\left(\lambda_{1} \mu_{3}\right)\left(\lambda_{2}\right)_{u}\right] \\
& n=\frac{1}{\Lambda}\left[\left(\lambda_{2} \mu_{3}\right)\left(\mu_{1}\right)_{u}-\left(\lambda_{1} \mu_{3}\right)\left(\mu_{2}\right)_{u}+\left(\lambda_{1} \mu_{2}+\lambda_{2} \mu_{1}\right)\left(\mu_{3}\right)_{u}\right] .
\end{aligned}
$$

On the other hand,

$\Gamma=r^{2}\left[(1-r p \sin u \cos \varphi \sin \theta)^{2}+(r p \cos u \sin \theta)^{2}\right]-\left[r \sin \theta+r^{2} p \cos \varphi \sin \theta\right]^{2}$.

So, the proof is complete.

Corollary 3.1. Assume the spin curve of a $\mathfrak{R}$-roller coaster surface is a unit speed curve $\beta: I \rightarrow \mathrm{E}^{3}$ with nonzero curvature. Then, mean curvature of $\mathfrak{R}$-roller coaster surface $\Psi^{\mathrm{R}}(s, u)$ is given by

$\mathrm{H}=\frac{1}{2 \Gamma \Lambda}\left[\left(\left(\lambda_{1}\right)^{2}+\left(\lambda_{2}\right)^{2}\right)\left[\left(\lambda_{2} \mu_{3}\right)\left(\mu_{1}\right)_{u}-\left(\lambda_{1} \mu_{3}\right)\left(\mu_{2}\right)_{u}+\left(\lambda_{1} \mu_{2}+\lambda_{2} \mu_{1}\right)\left(\mu_{3}\right)_{u}\right]\right.$

$-2\left(-r \sin \theta+r^{2} w \cos \varphi \sin \theta\right)\left[\left(\lambda_{2} \mu_{3}\right)\left(\lambda_{1}\right)_{u}-\left(\lambda_{1} \mu_{3}\right)\left(\lambda_{2}\right)_{u}\right]$

$+r^{2}\left[\left(\lambda_{2} \mu_{3}\right)\left(\left(\lambda_{1}\right)_{s}-w \lambda_{2} \sin \theta\right)+\left(\left(\lambda_{2}\right)_{s}+w \lambda_{1} \sin \theta\right)\left(-\lambda_{1} \mu_{3}\right)+\left(w \lambda_{2} \cos \theta\right]\right.$,

where

$\Gamma=r^{2}\left[(1-r p \sin u \cos \varphi \sin \theta)^{2}+(r p \cos u \sin \theta)^{2}\right]-\left[\left(r \sin \theta+r^{2} p \cos \varphi \sin \theta\right)\right]^{2}$.

Corollary 3.2. Assume the spin curve of a $\mathfrak{R}$-roller coaster surface is a unit speed curve $\beta: I \rightarrow \mathrm{E}^{3}$ with nonzero curvature. If $\frac{\partial \Psi^{\mathrm{R}}}{\partial t}$ is inextensible, then

$\frac{\partial}{\partial t}\left((1-r p \sin u \cos \varphi \sin \theta)^{2}+(r p \cos u \sin \theta)^{2}\right)=0$,

$\frac{\partial}{\partial t}\left(-r \sin \theta+r^{2} p \cos \varphi \sin \theta\right)=0$,

$\frac{\partial}{\partial t}\left(r^{2}\right)=0$

Corollary 3.3. Let be a $\mathfrak{R}$-roller coaster surface $\Psi^{\mathrm{R}}(s, u)$ and $\tilde{\Psi}^{\mathrm{R}}(s, u)$ be a parallel surface of $\Psi^{\mathrm{R}}(s, u)$ in Euclidean 3-space. Then, the equation of $\tilde{\Psi}^{\mathrm{R}}(s, u)$ is given by

$$
\begin{aligned}
& \tilde{\Psi}^{\mathrm{R}}(s, u)=\gamma(s)+r \cos u \mathbf{c}(s)+r \sin u(\cos \varphi(s) \mathbf{v}(s)+\sin \varphi(s) \mathbf{h}(s)) \\
& +\Theta\left(\frac{1}{\Lambda}\left[\left(\lambda_{2} \mu_{3}\right) \mathbf{c}-\left(\lambda_{1} \mu_{3}\right) \mathbf{v}+\left(\lambda_{1} \mu_{2}+\lambda_{2} \mu_{1}\right) \mathbf{h}\right],\right.
\end{aligned}
$$

where $\Theta$ is a constant.

Corollary 3.4. If $\varphi=\frac{\pi}{2}, \mathrm{r}=\frac{\mathrm{u}}{\sin \theta}$ and $u=\theta$ in equation (14), coincide with the equation [13]-7. 


\section{Examples}

\section{Example 4.1.}

First, let us regard a unit speed circular helix by

$$
\xi=\xi(s)=\left(a \cos \frac{s}{d}, a \sin \frac{s}{d}, \frac{b s}{d}\right),
$$

where $d=\sqrt{a^{2}+b^{2}} \in R$.

$$
\begin{aligned}
& p \sin \theta=\frac{a}{d^{2}}, \\
& p \cos \theta=\frac{b}{d^{2}}, \\
& \mathbf{c}=\frac{1}{d}\left(-a \sin \frac{s}{d}, a \cos \frac{s}{d}, b\right), \\
& \mathbf{v}=\left(-\cos \frac{s}{d},-\sin \frac{s}{d}, 0\right), \\
& \mathbf{h}=\frac{1}{d}\left(b \sin \frac{s}{d},-b \cos \frac{s}{d}, a\right),
\end{aligned}
$$

Thus, we obtain

$$
\begin{aligned}
& \Psi_{1}^{\mathrm{R}}(s, u)=\left(a \cos \frac{s}{d}-\frac{r a}{d} \cos u-\sin \frac{s}{d}-r \sin u \cos \varphi \cos \frac{s}{d}+\frac{r b}{d} \sin u \sin \varphi(s) \sin \frac{s}{d},\right. \\
& a \sin \frac{s}{d}+\frac{r a}{d} \cos u \cos \frac{s}{d}-r \sin u \cos \varphi \sin \frac{s}{d}-\frac{r b}{d} \sin u \sin \varphi \cos \frac{s}{d}, \\
& \left.\frac{b s}{d}+\frac{r}{d} \cos u+\frac{r a}{d} \sin u \sin \varphi(s) \frac{1}{d}\right) .
\end{aligned}
$$

By using above equation we have following figure:

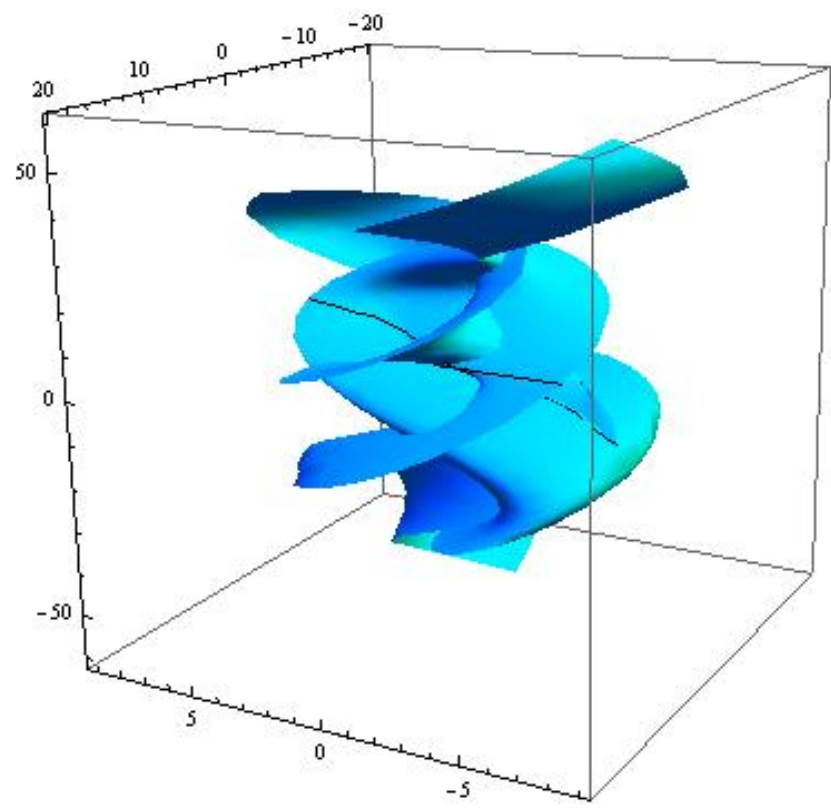

Figure 2. Roller Coaster surface $\Psi_{1}^{\mathrm{R}}(s, u)$. 


\section{Example 4.2.}

Let us take the unit speed space curve

$$
\begin{aligned}
& \xi=\xi(s)=\left(\frac{\sqrt{3}}{2} \sin s, \frac{s}{2}, \frac{\sqrt{3}}{2} \cos s\right), \\
& \mathbf{c}(s)=\left(\frac{\sqrt{3}}{2} \cos s \frac{1}{2}, \frac{1}{2},-\frac{\sqrt{3}}{2} \sin s\right), \\
& \mathbf{v}(s)=(-\sin s, 0,-\cos s), \\
& \mathbf{h}(s)=\left(-\frac{1}{2} \cos s, \frac{\sqrt{3}}{2}, \frac{1}{2} \sin s\right) .
\end{aligned}
$$

On the other hand,

$$
p(s) \cos (\theta(s))=\frac{1}{2} \text {. }
$$

$\Psi_{2}^{\mathrm{R}}(s, u)=\left(\frac{\sqrt{3}}{2} \sin s+\frac{\sqrt{3} r}{2} \cos u \cos s \frac{1}{2}-r \sin u \cos \varphi \sin s-\frac{r}{2} \sin u \sin \varphi \cos s\right.$,

$\frac{s}{2}+\frac{r}{2} \cos u+\frac{\sqrt{3} r}{2} \sin u \sin \varphi$,

$\left.\frac{\sqrt{3}}{2} \cos s-\frac{\sqrt{3} r}{2} \cos u \sin s-r \sin u \cos \varphi \sin s+\frac{r}{2} \sin u \sin \varphi \sin s\right)$.

By using above equation we have following figure:

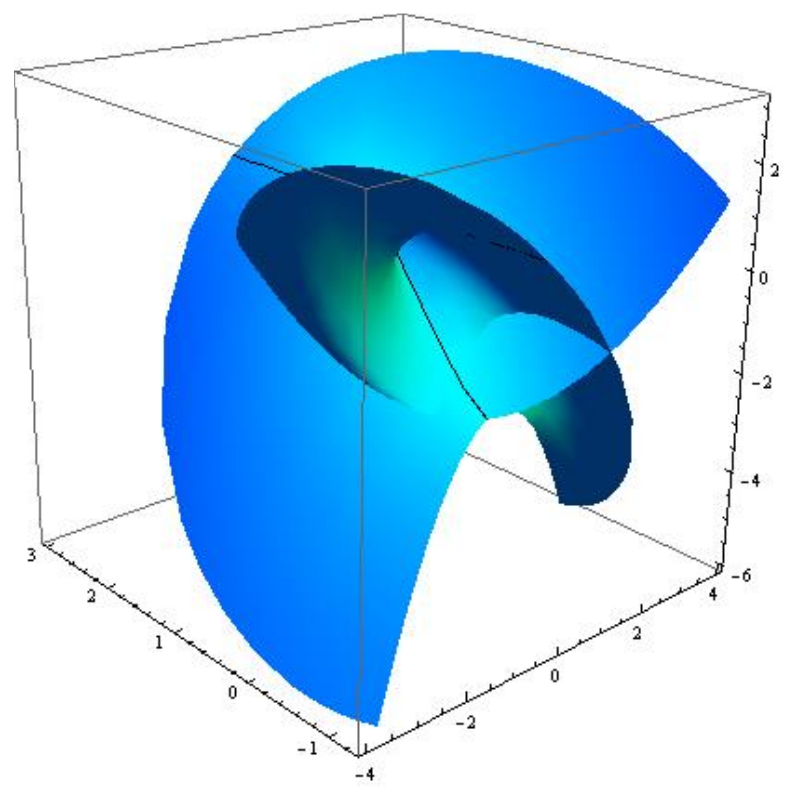

Figure 3. Roller Coaster surface $\Psi_{2}^{\mathrm{R}}(s, u)$. 


\section{References}

[1] Hollis S. 1999. Mathematica(1) Roller Coasters, Mathematica in Education and Research, 8 (3): 1619.

[2] Karacan M.K., Es H., Yaylı Y. 2006. Singuler Points of Tubular Surface in Minkowski Surfaces, Sarajevo Journal Mathematics, 2 (14): 73-82.

[3] Bükcü B., Karacan M.K. 2007. An Alternative Moving Frame for Tubular Surfaces around Timelike Curves in the Minkowski 3-space, Balkan Journal of Geometry and Applications, 12 (2): 73-80.

[4] Dogan F., Yaylı Y. 2011. On the Curvatures of Tubular Surfaces with Bishop Frame, Commun. Fac. Sci.Univ. Ank. Series A1, 60 (1): 59-69.

[5] Lu W., Pottmann H. 1996. Pipe Surfaces With Rational Spine Curve Are Rational, Computer Aided Geometric Design, 13 (7): 621-628.

[6] Körpınar T., Turhan E. 2012. On Characterization of B-canal Surfaces in terms of Biharmonic BSlant Helices according to Bishop Frame in Heisenberg Group Heis ${ }^{3}$, Journal Mathematics Analysis Applications, 382 (1): 57-65.

[7] Xu Z., Feng R.,Sun J.G. 2006. Analytic and Algebraic Properties of Canal Surfaces, Journal of Computational and Applied Mathematics, 195 (1-2): 220-228.

[8] Körpınar T., Turhan E. 2014. Time-Canal Surfaces Around Biharmonic Particles and Its Lorentz Transformations in Heisenberg space-time, International Journal Theoretical Physics, 53 (5): 15021520.

[9] Carmo M.D. 1976. Differential Geometry of Curves and Surfaces, Prentice Hall, New Jersey.

[10] Abdel-Baky R.A., Unluturk Y. 2016. On the Curvatures of Spacelike Circular Surfaces, Kuwait Journal of Science, 43 (3): 50-58.

[11] Izumiya S., Saji S., Takeuchi N. 2005. Circular Surfaces, Commun Advances in Geometry, 7 (2): 295-313.

[12] Cui L., Wang D., Dai J.S. 2009. Kinematic Geometry of Circular Surfaces With a Fixed Radius Based on Euclidean Invariants, Journal of Mechanical Design, 131 (10): 101009-1-9.

[13] Bohr J., Markvorsen S. 2013. Ribbon Crystals, Plos one, 8 (10): e74932.

[14] Baş S., Körpınar T., Sarıydın M.T. 2017. A New Approach Inextensible Flows of Curves with Ribbon Frame, Prespacetime Journal, 8 (12): 1350-1356.

[15] Kwon D.Y., Park F.C., Chi D.P. 2005. Inextensible Flows of Curves and Developable Surfaces, Applied Mathematics Letter, 18 (10): 1156-1162. 